\title{
ERÊNDIRA E SUA AVÓ: UM ESTUDO SOBRE A FEMINILIDADE
}

\section{Ruth Rissin (*)}

\section{UMA HISTÓRIA DE SEPARAÇÃO}

A incrivel e triste história da Cândida Erêndira e sua avó desalmada, de Gabriel García Márquez, é uma história de separação, de uma separação quase impossível.

Isoladas do mundo numa casa que é um "refúgio incompreensível" vivem Erêndira e sua avó. Em volta da casa há apenas o deserto e um punhado de índios. Dentro, um mundo disparatado que tenta recompor o fausto de uma antiga grandiosidade. São excessivos os relógios, os tapetes, os cristais e tantos outros objetos.

Vivem a avó e a neta num universo simbiótico, protegidas dos perigos da cidade, dos homens e da lei. Muito tempo antes, um contrabandista chamado Amadís tirou a avó de Erêndira de um prostíbulo depois que ela matou um homem e levou-a para o deserto, onde tiveram um filho, também chamado Amadís. Anos depois chegou Erêndira, filha bastarda do jovem Amadís, "uma lagartixa enrolada em panos", que passou a ser criada pela avó.

Mortos os dois Amadís, apenas elas permanecem naquela casa onde nada acontece, onde as cenas do cotidiano consistem tãosomente em evocações das lembranças da avó.

Erêndira tem a função de preparar e pôr em ação um cenário que dá ensejo à representação diária das recordações daquela mulher magnífica em seu teatro atemporal. Além de dar corda durante horas na infinidade de relógios, Erêndira cuida para que os tapetes estejam sempre lavados, os cristais, lustrados, prepara e coloca o almoço numa

Psicanalista, Membro da APERJ, mestre em Teoria Literária - UFRJ.

GARCIA MÁRQUEZ, p. 95; a partir daqui, nas referências a este texto só constará a abreviatura G.M. seguida do número da página a que se refere.

2 G.M., p.116. 
mesa de banquete com serviço para doze pessoas, e arruma a avó banha, penteia desembaraçando cada fio de cabelo, veste e, finalmente, faz a completa maquiagem da avó.

Assim, esse mundo não está isolado apenas do ponto de vista espacial mas também funciona fora das referência temporais. Não há acontecimentos mas tão-somente a encenação repetitiva de cenas do passado. Os dois Amadís, pai e filho, são indistintos no nome, no tempo e no papel que exercem. Fracassam ao se deixarem matar, tornando prescindível a figura masculina e permitindo que a avó reine absoluta em sua onipotênciá.

Tão grande é seu poder que seu nome nem pode ser pronunciado. No texto, é chamada na maioria das vezes como "a avó". As outras referências são apenas uma vez como "a Dama", numa outra vez como "rainha".

Erêndira não possui existência própria. Quase nunca fala. Só o faz "por motivos insdiscutíveis". ${ }^{4} \mathrm{Em}$ geral e, principalmente, no primeiro capítulo, quem fala é a avó, dando infindáveis ordens à neta que apenas responde: "Sim, avó". Erêndira aceita passivamente seu comando, de maneira que as duas acabam formando um conjunto indissociável, concretizando de forma extrema a forte ligação entre filha e mãe, figura que na novela de García Márquez aparece transmutada na personagem da avó. Para andar, para se vestir, para fazer quase tudo, a avó precisa de Erêndira. Mesmo dormindo, continua a monitorar a neta através de ordens pronunciadas no meio do sono.

A fala da avó não se acaba nem mesmo quando está dormindo. Sonha e fala, suas palavras descrevem as imagens de seus sonhos. A neta escuta a descrição e compartilha assim dos sonhos da avó, de maneira que continuam a não existir fronteiras entre elas.

O "vento da desgraça" de Erêndiras aparece repetidamente ao longo do primeiro capítulo como um refrão que pontua toda essa parte do texto, prenunciando o acidente. Este acontece sob a forma do incêndio que ameaça a unidade simbiótica e obriga avó e neta a abandonarem seu refúgio e saírem para o mundo. Não é por acaso que

\footnotetext{
G.M., p.153.

G.M., p.64.

G.M., p.92, 96 et passim.
} 
Garcia Márquez se utiliza do animismo ao descrever a ação do vento "enquanto o vento dava voltas ao redor da casa, buscando um vão para entrar"; "' "o vento de sua desgraça meteu-se no quarto como uma matilha de cães".?

Animado pelo ódio de Erêndira, o vento ganha capacidade de ação, derruba o candelabro provocando o incêndio que destrói completamente a casa da avó.

A não deliberada tentativa de libertação está fadada ao fracasso. Findo o incêndio, a situação pouco se modifica e Erêndira continua escravizada à avó. Está agora atrelada a ela por uma dívida concreta e que cada vez mais se mostrará impagável.

Rompido o casulo, saem as duas mundo afora. De certa maneira, algum elemento temporal se introduz, as cenas já não se limitam à vivificação do imaginário da avó aparecendo novos cenários e tornando-se elas então mais vulneráveis ao assédio de outros personagens. Porém, a relação simbiótica persiste e o afastamento entre elas ainda está bem longe de ser possível.

A avó determina que Erêndira deverá compensá-la pelas perdas do incêndio (reconhecendo assim sua autoria) e, para isso, a prostitui. Caminham de cidade em cidade e, como antes do incêndio, Erêndira não fala, não decide nada, apenas responde: "sim, avó". Não é dona de seu corpo. a avó que continua a falar, é ela que administra o corpo da neta, quem escolhe quais e quantos serão os parceiros de Erêndira. É também ela quem faz as contas, contabilizando perdas e gastos cada vez maiores, totalizando uma dívida também cada vez maior.

Para tornar-se mulher, ser dona de seu corpo, de seu desejo e prazer, é preciso separar-se da mãe-avó e isto, por enquanto, é impossível para Erêndira. Por isso, sua atividade sexual é necessáriamente a "prisão mortal da cama". A dívida é a resultante de vetores ambivalentes, em equivalência à ambivalência experimentada na relação com a mãe-avó. Deve à mãe a condição feminina, mas ainda não pode tirar prazer desta condição.
G.M., p.97.
G.M., p.99.
G.M., p. 123. 
Certo dia, um grupo de missionários leva Erêndira para um convento mantendo-a sob custódia, longe da avó.

No convento, à revelia da avó, continuando um processo que começou com o incêndio, Erêndira aprende um pouco mais sobre o mundo, conhecendo "outras formas de beleza e horror que nunca imaginara no mundo estreito da cama". Foi lá que, ao ouvir uma freira tocando um clavicórdio, abriu a boca para falar pela primeira vez: — "Sou feliz."

Mas, apesar desses momentos de felicidade, ao se deparar novamente com a avó, "Erêndira encontrou-se de novo sob o feitiço que a dominava desde o seu nascimento".E, diante da avó impassível, quando lhe perguntaram qual era a sua vontade livre, verdadeira e definitiva, não teve nem um suspiro de vacilação:

- [...] Vou com minha avó. ${ }^{10}$

Essa relação que aparece para Erêndira como um feitiço, que chega a ser mais forte que a própria felicidade, tem a contrapartida no apego da avó a Erêndira. Quando esta se vai para o convento, a avó se coloca na porta sem ser afastar por um só momento. Não mexe nenhuma vez a cabeça "para não afastar a vista do convento". " Há uma relação de mão dupla em que prisioneira e carcereira estão enredadas na mesma teia de dependência.

Muitas são as razões para essa ligação tão complexa, muitas são as razões para a ambivalência, e elas são peculiares à relação entre mãe e filha representada no texto pela relação entre a avó e Erêndira.

Tendo sua origem nas fases mais arcaicas da vida da menina, a mãe primitiva aparece para esta como dotada de poderes espetaculares, - o feitiço que prende Erêndira.

O desenvolvimento da menina leva-a à constatação de que não possui um pênis e acusa a mãe por essa falta. ${ }^{12}$ Tal acusação, que vem acompanhada de ressentimento, ao mesmo tempo que afasta a menina da mãe, coloca-as lado a lado ao fazê-las compartilhar a mesma condição. A constatação de que é desprovida de pênis impulsiona a

\footnotetext{
9 G.M., p.124.

10 G.M., p.127.

11 G.M., p.121.

12 Cf. Freud (1925).
} 
menina no sentido do afastamento mas ao mesmo tempo marca esse movimento com ressentimento e ambivalência. ${ }^{13}$

A menina precisará desgarrar-se da mãe, apesar do feitiço, para entrar na relação com o objeto masculino. Relacionar-se com o homem é relembrar sua diferença, a ausência de pênis, a inveja que essa diferença provoca. ${ }^{14}$

Erêndira e sua avó protegem-se mutuamente da relação com os homens, dessa relação que é tão irresistível quanto aterrorizadora, como conta a avó ao sonhar uma de suas lembranças:

Eu punha duas trancas no quarto para que não entrasse, punha a penteadera e a mesa contra a porta e as cadeiras sobre a mesa, e bastava que ele desse um golpezinho com o anel para que os parapeitos desabassem, as cadeiras descessem da mesa, a mesa e a penteadeira se afastassem sozinhas, as trancas saíssem sozinhas das argolas. ${ }^{15}$

O desejo da avó torna mágico e potencializa o poder do homem. Mas desencadeia tambem o ódio por todo o desejo que o homem, esse ser diferente, é capaz de provocar na mulher. Neste caso, o ódio é mortal:

Suplicando intimamente que a porta se abrisse sem se abrir, que ele entrasse sem entrar, que não fosse embora nunca, mas que também não voltasse jamais, para não ter que matá-lo [...].

- Eu o preveni, e ele riu - gritava [ a avó] -, voltei a preveni-lo e voltou a rir, até que abriu os olhos aterrados, dizendo, ai, rainha ! ai, rainha!, e a voz não the saiu pela boca mas pela facada na garganta. ${ }^{16}$

Mais um quesito das contas a serem ajustadas entre mãe e filha, a maternidade é vivida como uma perda imposta à mãe-avó. Não era ela a mulher "mais bela do mundo", 17 que abdicou de todos os homens, de tantos prazeres para recolher-se naquele refúgio? Não é

\footnotetext{
13 Cf. Freud (1931).

14 Cf. Freud (1918[1917]).

15 G.M., p.152.

16 G.M., p.152-153.

17 G.M., p.122.
} 
como a mulher mais bela do mundo que através de seu olhar enfeitiçado a menina vê a mãe?

A adolescência da filha é um complicador pois está vivendo agora tudo aquilo que a mãe, de alguma maneira, perdeu. É ela quem detém agora o poder de sedução, ocupando ou tirando o lugar que era antes ocupado pela mãe.

$\mathrm{Na}$ história de Erêndira, chega um dia Ulisses, meio anjo, meio adolescente, de qualquer maneira alguém que também ainda sabe pouco do amor. Esse personagem, aparentado ao $\operatorname{Eros}^{18}$ da mitologia grega, que, como este, aparece furtivamente no meio da noite, ${ }^{194}$ é capaz de despertar Erêndira, fazê-la esquecer o cansaço, despertar seu desejo. Com ele Erêndira começa a existir, a reagir, em lugar de obedecer como acontece na relação com a avó: "Fez uma imitação tão real do pio da coruja que os olhos de Erêndira sorriram pela primeira vez",20

Com ele Erêndira torna-se por momentos dona de seu corpo. A partir do encontro com Ulisses Erêndira começa, na descrição das ações, a fazer parte do sujeito verbal:

mas a contemplou com tanta intensidade que Erêndira acordou. Então se beijaram na escuridão, acariciaram-se sem pressa, despiram-se vagarosamente. ${ }^{21}$

Ulisses ajudará Erêndira a separar-se da avó. Ao feitiço da avó que escraviza anulando a vontade, Ulisses opõe a magia do amor. Enquanto a avó penetra e invade os pensamentos da neta, entre Ulisses e Erêndira há uma comunicação mágica que os faz, apesar da distância, ouvir os murmúrios e gritos mútuos, adivinhar paradeiros:

[Erêndira ] logo se deitou como um afogado, com os braços no peito e os olhos abertos, e chamou com toda a força de sua voz interior:

- Ulisses.

Ulisses despertou de repente na casa do laranjal. [...]

\footnotetext{
18 Aliás, não seria esta a origem do nome de Erêndira?

19 Cf. Brandão.

20 G.M., p.133.

21 G.M., p.148.
} 
Nessa ocasião, Ulisses não teve de perguntar a ninguém pelo destino de Erêndira. ${ }^{22}$

Não será nada fácil para Ulisses libertar Erêndira da avó. Resistindo a "arsênico suficiente para exterminar uma geração de ratos", 23 a avó obriga Ulisses a um confronto mortal. O resultado, porém, ainda não pode ser a união de Erêndira e Ulisses.

A morte da avó vem dar o sentido do tempo que pela primeira vez é mencionado no texto e só então atinge Erêndira:

quando se convenceu de que [a avó] estava morta, seu rosto ganhou, de chofre, toda a maturidade da pessoa adulta que não the haviam dado seus vinte anos de infortúnio. ${ }^{24}$

Liberta da avó, Erêndira ganha marcas do tempo e torna-se, afinal, adulta, dona de seu corpo, sua dor, de seu desejo.

Mas não pode viver tudo isso ao lado de Ulisses. Este, "sentado junto ao cadáver [da avó], esgotado pela luta, quanto mais procurava limpar o rosto, mais o lambuzava com aquela matéria verde e viva". ${ }^{26}$ O sangue da avó cola-se a seu corpo, tornando inevitável que suas figuras estejam, para Erêndira, muito misturadas e ele, por demais marcado pelo assassinato que cometera.

\section{OUTRAS HISTÓRIAS}

A idéia deste trabalho surgiu no decorrer do tratamento da paciente, aqui chamada de Sandra, que dizia freqüentemente considerar-se semelhante a algum personagem de Cem Anos de Solidão, de Gabriel García Márquez. Com efeito, certos fatos de sua vida possuíam um caráter inusitado e os "personagens" de sua história tinham algumas características que eram levadas até as últimas consequências, fazendo realmente lembrar o realismo fantástico desse autor. No entanto, quando a ouvia, era em um personagem de outra

\footnotetext{
22 G.M., p.146-147.

23 G.M., p. 152.

24 G.M., p. 157.

25 Cf. Rissin.

26 G.M., p. 158.
} 
obra de García Márquez que eu pensava: Erêndira, da novela focalizada acima.

A relação que Sandra mantivera com sua mãe e, posteriormente, com a mãe de seu companheiro, possuía caracteristicas muito parecidas às da relação de Erêndira com sua avó.

Assim como Erêndira era escravizada pela avó sendo-lhe impostas tarefas infindáveis e absurdas, Sandra, quando menina, recebia da mãe ordens sucessivas. Primeiramente, era mandada à mercearia, em seguida, ao armarinho, depois, à padaria, num ir e vir incessante que a obrigava a estar à disposição da mãe.

Muitos anos depois, a mãe do seu companheiro passou a ter com ela uma relação semelhante. Sandra trabalhava em sua confecção, recebendo um salário irrisório, sem horário estabelecido. Trabalhava às vezes aos sábados e domingos, por mais de catorze horas seguidas. Algumas vezes, quando Sandra estava indo embora para casa, por volta da meia-noite, a sogra tinha a coragem de lhe pedir para ficar mais um pouco para pintar seu cabelo ou depilar as axilas.

Assim como Erêndira, Sandra também mostrava-se resignada. Uma resignação enganosa. Sandra,com o tempo, começou a contar que quando a mãe lhe pedia para ir à rua, muitas vezes acabava esquecendo de fazer alguma coisa, trazia coisas erradas, tropeçava no caminho ou quebrava a garrafa do refrigerante que tinha ido comprar. Esses protestos mudos se aparentavam, em escala reduzida, ao incêndio da casa da avó de Erêndira.

$\mathrm{Na}$ escola, Sandra sempre perdia borrachas e apontadores que, por serem pobres, eram comprados com sacrifício. Sua mãe ficava com muita raiva e a surrava, deixando marcas nos braços e pernas.

Criava-se assim uma situação de curto-circuito em que ambas ficavam extremamente ligadas, protegidas contra a ameça de abandono, proteção confirmada pelo fato de que, até os 6 anos de idade, Sandra dormiu no quarto dos pais, segurando a mão de sua mãe.

Uma sempre solicitava a presença e atenção da outra - a mãe verificando constantemente os objetos que a filha teimava em perder, a filha fazendo continuamente tarefas para a mãe. O aspecto sadomasoquista reforçava o estreito vínculo e a impossibilidade do 
afastamento, atestando tanto o apego quanto a hostilidade e revelando todo o caráter ambivalente da relação.

Sandra foi crescendo, o movimento no sentido da independência foi se tornando mais forte, e ela passou a experimentar um sentimento de dívida em relação à mãe. Reconhecia que, apesar de tudo, esta fizera muito por ela. Afinal, Sandra era a caçula de seis filhos e foi criada numa situação mais confortável que a dos outros. Só ela conseguiu estudar e obter diploma universitário. Mas era impossível desenvolver-se porque isso significava afastar-se da mãe, traí-la e, de qualquer forma, perdê-la. Desta maneira, a gratidão pelo que a mãe fizera era impossível, misturando-se à angústia de separação e à ambivalência. O resultado era um sentimento de dívida que possuía um caráter impagável, semelhante à dívida de Erêndira com a avó.

Muitas outras características da relação de Erêndira com a avó vão se repetir na análise de inúmeras outras mulheres. Parece impossível afastar-se dessa figura majestosa que, como na novela de García Márquez, mostra-se onipotente, capaz de adivinhar os pensamentos de Erêndira ${ }^{27}$, de impor sua vontade e enfeitiçá-la. ${ }^{28}$

Rosa, de 23 anos, é a caçula de três filhas. É a única solteira. Vive com a mãe, divorciada há muitos anos. Obesa, aposentada por doença mental, permanece em casa a maior parte do tempo. Apegada à mãe e com dificuldade para se relacionar com amigos e namorados, Rosa teme ter o mesmo destino: permanecer solitária, sem companheiro, em casa, "comendo sem parar". Atormentada com a idéia de seu peso excessivo, faz várias dietas alimentares. Nessas ocasiões, a mãe esmera-se em fazer vários doces aos quais Rosa é incapaz de resistir. Fica revoltada e sua sensação é de impotência diante do que descreve como a vontade de a mãe provar que sempre poderá dominá-la, dobrar sua vontade.

Mais do que resistir a aspectos em que se identifica com a mãe (tendência ao isolamento, à obesidade), Rosa reluta em entregar-se ao "feitiço" dessa relação tão protetora quanto aniquiladora.

Assim como era impossível para Erêndira ligar-se a um homem, para a paciente que chamarei de Maria Regina foi muito

\footnotetext{
27 G.M., p. 146.

28 G.M., p. 127.
} 
difícil casar-se. Seu noivo trabalhava na Marinha, passando três meses viajando e um mês no Brasil. Casaram-se e saíram em lua-de-mel aproveitando uma das viagens do marido para o exterior. Maria Regina sentiu-se muito mal durante a viagem e no período que se seguiu, a ponto de pensar em se separar. Permaneceram juntos depois da lua-de-mel mas, a partir daí, durante todas as viagens do marido, Maria Regina voltava para a casa dos pais. Sempre que se aproximava a época de o marido voltar, Maria Regina apresentava inúmeros sintomas de ansiedade. Além disso, acreditava-se despreparada para cuidar da casa, capacidade que só atribuía à mãe. Achava que só ela era capaz de gerenciar a casa, cozinhar, realizar as tarefas necessárias. Quando estava com o marido em casa, tinha a impressão de estar "brincando de casinha", como se não fosse "de verdade".

A partir de um certo momento, Maria Regina passou a ficar em casa durante as viagens do marido. Mas achava que a mãe torcia para que Maria Regina voltasse para lá. Em sua opinião, ela parecia sentir-se vitoriosa quando isto acontecia. Certa vez, quando se aproximava a data da partida do marido, a mãe lhe disse, segundo ela, num tom de profecia: "Que bom que na próxima semana o Charles (o cão de minha cliente) e a Maria Regina vão dormir aqui".

Maria Regina tinha um único irmão, mais novo do que ela dois anos e meio. Certa vez, quando eram pequenos, a mãe levou o irmão ao médico e Maria Regina acompanhou-os, ficando na sala de espera enquanto o irmão era atendido. Passou muito tempo e eles não saíam do consultório. Maria Regina começou a imaginar inúmeras coisas, que haviam saído por outra porta, que a mãe nunca mais voltaria.

No decorrer do tratamento, foi se desenvolvendo profissionalmente e tomando atitudes empreendedoras, assim como aproximou-se mais do marido e ensaiou passar mais tempo em sua própria casa durante as viagens deste. A partir dessas mudanças, Maria Regina começou a ter medo de que a mãe morresse. O desenvolvimento e o conseqüente afastamento reativaram a angústia de separação e a culpa.

Ao deixar de ser tão necessária, a mãe agora pode e vai, certamente, morrer. Esta fantasia tão frequente no imaginário feminino tem diversos desdobramentos relacionados com todo o percurso necessário à mulher em sua conquista da feminilidade. 


\section{UMA HISTÓRIA A SER CONSTRUÍDA}

Muitas são as razões para a dificuldade de desligamento entre mãe e filha. Freud, que iniciou a pesquisa psicanalítica defrontando-se com a questão feminina, somente após um longo período começou a se deter mais demoradamente no estudo das particularidades do desenvolvimento psicossexual da menina.

Na década de 20, escreve alguns artigos - A Organização Genital Infantil, A Dissolução do Complexo de Édipo e Algumas Consequências Psíquicas da Distinção Anatômica entre os Sexos onde parte do reconhecimento da existência de uma fase fálica nas crianças de ambos os sexos, para abordar as consequências da constatação das diferenças anatômicas com as subsequentes angústia de castração, no menimo, e a inveja do pênis, na menina, que a faz voltar-se para o pai como objeto amoroso.

Através desses artigos, Freud prepara o caminho para os trabalhos de 1931 e 1932, Sexualidade Feminina e Feminilidade e para o artigo que elaborou em conjunto com Ruth Mack Brunswick, escrito e publicado por ela mais tarde, A Fase Pré-Edipiana do Desenvolvimento Libidinal.

Nestes trabalhos Freud dá a devida importância ao intenso apego da menina à mãe bem como à ambivalência da relação entre elas. $^{291}$ A feminilidade passa a ser vista como um caminho a ser percorrido, um caminho pontilhado de obstáculos.

A ambivalência e a dificuldade de afastamento são justificadas pelos diversos motivos que levam a menina a hostilizar sua mãe. Destes, alguns são inespecíficos às crianças dos dois sexos, como o ciúme de outras pessoas que impedem a dedicação exclusiva da mãe à criança. ${ }^{30}$

Outra razão para a hostilidade, aponta Freud, é a proibição da masturbação. ${ }^{31}$ Fica mais difícil ainda aceitar essa proibição porque foi a própria mãe quem despertou, através dos cuidados corporais, as sensações prazerosas que provavelmente servirão como modelo para a atividade masturbatória.

\footnotetext{
29 Freud (1931), p.260.

30 Freud (1931), p.266.

31 Freud (1931), p.267.
} 
Outra acusação feita à mãe, agora especificamente pela menina, ocorre por ocasião da constatação da ausência de pênis. Esta ausência é vista inicialmente como somente sua, como algo que a mãe recusou-se a lhe dar. Em seguida, a menina vai reconhecer a mesma ausência em outras mulheres, até que finalmente a percebe na própria mãe. ${ }^{32} \mathrm{O}$ que se torna motivo para novas acusações: a mãe é agora depreciada, além de tirar as últimas esperanças de a filha vir um dia a ter esse órgão.

Para Freud, mais do que tudo, a ambivalência é uma conseqüência do fato dessa relação ser a primeira e de ser tão intensa, estando mãe e filha em posições desiguais, o que dá margem a inúmeros desapontamentos.

O afastamento é uma tentativa de resolução dos sentimentos de ódio, mas nem sempre pode ser conseguido em função dos fortes laços que continuam a existir. ${ }^{332}$ Erêndira expressa esse impasse de forma clara no momento em que pede a Ulisses para matar sua avó. Ulisses lhe pergunta por que ela mesma não o faz e Erêndira responde: “-Eu não posso, é minha avó". ${ }^{343}$

Inúmeros autores abordarão outros aspectos dessa relação. Destacaremos algumas dessas idéias, relacionadas com a novela estudada e com os casos relatados.

Ruth Mack Brunswick, no trabalho citado acima, aprofunda a temática da mãe fálica. Segundo a autora, a fálica é uma fantasia que surge em consequência da constatação da ausência de pênis na menina. ${ }^{35}$ A menina percebe que não o tem, mas ainda acredita que a mãe o possui. Afinal, ela sempre foi vista como a ativa, a provedora, e o conceito de mãe fálica vem alimentar a idéia de que a mãe continua sendo onipotente, capaz de tudo e possuidora de tudo o que é valioso. $^{36}$

A mãe é idealizada, admirada, invejada pela filha no que esta vê como sua grandeza. Tudo o que ela faz com a filha se tornará o modelo de suas fantasias e de seus desejos. A cena primária, bem

\footnotetext{
Freud (1931[1932]), p.156.

Freud (1932[1931]), p.163.

G.M, p. 150.

Cf. Brunswick.

Brunswick, p.304.
} 
como as fantasias concomitantes à masturbação, carregam a marca de seus gestos, de suas carícias. A criança deseja, por um lado, satisfazêla e, por outro, ser completamente atendida por ela. Sente-se protegida por essa mulher poderosa, o que lhe dá uma certa garantia, mas, por outro lado, a coloca numa posição de permanente desvantagem quando se compara com ela..

Da mesma maneira que o menino, a menina quer presentear a mãe com um filho. A decepção pela impossibilidade de realizar esse desejo vai ser um dos fatores determinantes da entrada da menina no Édipo, mas muitas vezes será responsável pela impossibilidade de obter uma identidade sexual, levando a menina - embora essa eventualidade também possas ocorrer no caso do menino - a adotar o que Ruth Mack Brunswick descreve como o papel do pajem, que "na época é quase sempre desempenhado por mulheres e que personifica esse tipo de atividade característica [...] da criança sexualmente indiferenciada". 376

Para a autora, a constatação da ausência de pênis na mãe, além da perda da esperança de a menina vir um dia a possuir um pênis, vai determinar também a perda da mãe enquanto objeto amoroso. Esta perda, que ocorre nas crianças de ambos os sexos, é, para a menina, mais amarga do que para o menino. Para este, representa a proteção de seu pênis, sendo, portanto, uma esperança em relação ao futuro, enquanto que para a menina representa a necessidade da aceitação de uma desesperança. Para a autora, ainda, a tentativa de substituir o objeto amoroso, isto é, a busca do pai, é também muito dificultada pela intensidade e tenacidade de sua ligação com a mãe.

Marie Madeleine Chatel focaliza inicialmente o desejo de um filho como substituto para o irrealizável desejo do pênis na mulher. Quando nasce um menino, a mãe reconhece de imediato o pênis como a marca de uma diferênça, como traço separador de imagem corporal. Além disso, sendo o portador do traço fálico, ele satisfaz duplamente o desejo de pênis, da mãe: ele é o filho-falo, portador-de-falo.

A menina, por outro lado, possui o mesmo órgão genital da mãe. Não apresenta de imediato o traço diferencial, separador da imagem corporal, não conseguindo se inscrever no imaginário daquela

37 Brunswick, p.130. 
como corpo separado, tornando difícil a discriminação da mãe em relação à filha.

Por não possuir o traço fálico, a menina é menos capaz de substituir satisfatoriamente o desejo de pênis da mãe, provocando nesta uma decepção.

A menor discriminação provoca uma "comunhão de imagens entre mãe e filha" ${ }^{38}$ que cria na mãe uma dificuldade de construir traços simbólicos que sustentem a separação da filha. A consequência, segundo a autora, é a instauração de "uma rivalidade sem nome" entre mãe e filha. Para esta, a mãe é uma rival que não lhe permitiria ter um marido e, menos ainda, um filho, como aparece na temática da paciente que chamamos de Maria Regina. Isto seria vivido como um desafio à mãe. A filha sente pavor diante da idéia de suplantá-la, ficando extremamente ameaçada com a possibilidade de ser atingida por um ódio destruidor, por represálias, temendo, enfim, perder a mãe. A busca do pai, e posteriormente de um marido é, portanto, muito difícil. Seu custo é o risco de perder o objeto materno.

Já em 1918, no artigo O tabu da virgindade, Freud trata, através de um outro ângulo, dessa questão das semelhanças e diferenças. Como vimos na análise da novela de García Márquez, é muito ameaçador, para a mulher, o confronto com um ser tão diferente quanto o homem. Implica a reatualização das reações experimentadas por ocasião da constatação da diferença anatômica, e faz reativar a inveja do pênis. Aliando-se ao medo de perder a mãe, o refúgio na relação com ela é uma proteção contra tais experiências dolorosas.

No trabalho intitulado $O$ enigma da feminilidade na obra de Freud, Danièle Brun trata de inúmeras questões referentes à importância da relação entre mãe e filha.

A autora destaca, na obra de Freud, que o "enigma da feminilidade" está estreitamente ligado à renúncia e à mudança e reagrupa as afirmações freudianas em torno das diversas renúncias que a menina deve realizar.

Assim, a menina, no decorrer do processo de desenvolvimento, deve renunciar à mãe fálica, assim como à visão desta como onipotente, visão que tinha, entre outras, a função de

38 Chatel, p.5. 
protegê-la, de dar-lhe a ilusão de completude, da qual a menina também deve abrir mão.

Além disso, a renúncia à mãe é a renúncia ao primeiro objeto de amor e, como vimos, à ilusão de obter no futuro, um pênis. Enfim, a menina é obrigada a renunciar ao falo.

Danièle Brun aponta para o caráter melancólico desse conjunto de renúncias que a menina precisa realizar.

Baseando-se nessa idéia das renúncias e em dois trabalhos de Freud, O ego e o id (1923) e Luto e melancolia (1917[1915]), Daniéle Brun $^{39}$ desenvolve a hipótese de que a inveja do pênis teria origem ainda mais arcaica que a do momento edipiano, referindo-se à inveja da mãe fálica primitiva.

Em Luto e melancolia, Freud descreve o processo em que o objeto perdido é incorporado ao ego através do processo da identificação. Esta perda não é necessariamente provocada pela morte, mas pode resultar de várias situações em que se sofre um prejuízo ou decepção, situações que façam intervir na relação uma oposição entre amor e ódio, ou reforçar uma ambivalência já existente (poderíamos acrescentar: como o processo vivido pela menina em relação à mãe).

Anos mais tarde, em $O$ ego $e o i d$, Freud afirma que esse processo é muito mais freqüente do que imaginava, especialmente nas fases primitivas do desenvolvimento, possuindo ainda o poder de determinar o caráter do indivíduo, sendo "o ego um precipatado de investimentos objetais abandonados que contém a história dessas escolhas de objeto". ${ }^{40}$ Deste ponto de vista, conclui Daniéle Brun, a gênese da inveja do pênis pode ser relacionada "à perda da mãe enquanto objeto da primeira infância". ${ }^{41}$ Assim sendo, é possível considerar as "manifestações da inveja do pênis na vida psíquica da mulher como os vestígios de um processo melancólico" 42 que dão, portanto, uma determinada coloração ao caráter da menina, devendose atribuir à etapa primitiva em que se originaram e à forma como esses vestígios se integraram à vida psíquica, "as dificuldades relativas

\footnotetext{
Brun, p.137-138.

Freud (1923, p.43).

Brun, p.137

Brun, p.137.
} 
às modificações do caráter no curso de uma análise". ${ }^{43}$ Esses vestígios seriam responsáveis também pela "atemporalidade da imagem da mãe e dos afetos paradoxais de ódio amoroso que ela sustenta". ${ }^{4}$

Em outro estudo, Inveja da vagina, a mesma autora trata do momento, que ocorre geralmente na adolescência, em que a jovem realiza uma modificação da imagem da mãe.

À medida que vai crescendo e em função das experiências por que vai passando, a menina adquire um conhecimento de sua vagina que leva à conscientização de que a mãe tem uma dupla função materna e de mulher. Tomar conhecimento da vagina é, também, conhecer essa outra mulher, aquela que "a mãe foi antes de ter o filho, uma mulher que a filha pode imaginar como sedutora ou, pelo contrário, temerosa com os homens, frígida, talvez", ${ }^{45}$ mas, de qualquer maneira, alguém que passa a ser vista de uma forma diferente.

A mudança na imagem da mãe reatualiza e ressignifica momentos anteriores, como as fantasias ligadas à cena primária, as situações de ciúme pré-edipianas ou edipianas. Obriga a filha a imaginar a mãe jovem como uma rival.

A autora considera esse trabalho psíquico como um verdadeiro matricídio, resultante "de um movimento de busca da mulher na mãe, movimento que exige a destruição da mãe familiar, cotidiana mas, não obstante, onipresente". ${ }^{46}$

É um processo que podemos acompanhar tanto na novela de García Márquez, quanto nos casos citados em seguida.

Um dos componentes da dívida de Erêndira para com sua avó é tudo o de que esta parece ter aberto mão ao recolher-se ao refúgio do casamento, como foi abordado na análise da novela.

As mulheres que foram descritas no tópico seguinte também se defrontam com a imagem da mulher na mãe. Sandra fala muito da beleza da mãe quando jovem. Por vezes diz-se parecida com ela, por vezes relata fantasias em que a imagina grávida, num confronto entre a fecundidade da mãe, que tivera muitos filhos, com a sua - Sandra

\footnotetext{
43 Brun, p. 138.

44 Brun, p.139.

45 Brun, p.33.

46 Brun, p.34
} 
achava que nunca conseguiria engravidar. Por vezes, imagina-a bela, num baile, cortejada por vários homens.

Maria Regina e Rosa rebelam-se, cada uma a seu modo, diante da possibilidade de suas mães terem uma vida sexual. Maria Regina ridiculariza o fato de sua mãe ter feito cirurgia plástica da face e do abdômen. "Quem ela quer conquistar ?", diz. Rosa, por sua vez, fica revoltada com o cirurgião que, numa cirurgia de aparelho genital de sua mãe, não fez a retirada completa de todos os órgãos, deixando uma parte que, segundo ela, permitiria à mãe "ter uma vida sexual mais prazerosa" mas que acarretaria um certo risco de recidiva. "Ele não sabia que ela não tem vida sexual ativa? Por que não perguntou ?", reclama. Não admite a hipótese de o cirurgião ter perguntado e sua mãe ter feito a escolha. É grande a raiva ao perceber que a mãe ainda possa pretender ter uma atividade sexual.

A violência que caracteriza as relações entre mãe e filha na adolescência e que prossegue em tempos mais tardios, justifica que esse desgarramento final seja nomeado matricídio. ${ }^{47}$

O resultado nem sempre é previsível - Erêndira, afinal, parte não se sabe para onde e todos nós constatamos que nem sempre nossas pacientes efetivam a separação. Mas o embate é inevitável e, dele, ninguém sai intacto. $O$ que pelo menos garante que haja, assim, a perspectiva de novas tentativas.

\section{REFERÊNCIAS BIBLIOGRÁFICAS}

BRANDÃO, Junito de Souza. Mitologia grega. Petrópolis: Vozes, 1992. vol. II.

BRUN, Daniéle. Figurações do feminino. São Paulo: Escuta, 1989. Inveja da vagina, p. 17-35. O enigma da feminilidade na obra de Freud, p. 97-145.

BRUNSWICK, Ruth Mack. The Preoedipal Phase of the Libido Development. Psychoanal. Q., 9:293-319, 1940.

CHATEL. Marie Madeleite. Le rapport mére-fille. s.d. Mímeo.

47 Brun. 
FREUD, Sigmund. Edição standard das obras completas de Sigmund Freud. Rio de Janeiro, Imago, 1980.

(1913) Totem e tabu. vol. XIII. p. 17-191.

(1917[1915]). Luto e melancolia. vol. XIV. p. 275-291.

(1918[1917]). O tabu da virgindade. vol. XI. p. 179-195.

(1923a). O ego e o id. vol. XIX. p. 23-75.

(1923b). A organização genital infantil. vol. XIX. p. 179-188.

(1924). A dissolução do Complexo de Édipo. vol. XIX. p. 217-228.

(1925). Algumas consequências psíquicas da distinção anatômica entre os sexos. vol. XIX. p. 309-320.

(1931). Sexualidade feminina. vol. XXI. p. 259-281.

(1933[1932]). Novas Conferências introdutórias sobre psicanálise.

Conferência XXXIII. Feminilidade. vol. XXII. p. 139-165.

GARCÍA MÁRQUEZ, Gabriel. A incrível e triste história da Cândida Erêndira e sua avó desalmada. Rio de Janeiro, Record, 1972.

RISSIN, Ruth. A Aquisição do Sentido da Temporalidade. Boletim científico SPRJ, 3-4: 34-47, 1991.

Autora :

Ruth Rissin

Rua Senador Euzebio 19 apto. 802

CEP 22250-080 Flamengo Rio de Janeiro RJ

Tel : (21) 25523561 (21) 25472998 (21) 96150627 